Check for updates

Cite this: J. Mater. Chem. A, 2021, 9 , 8692

Received 11th November 2020

Accepted 9th March 2021

DOI: $10.1039 / d 0 t a 11008 f$

rsc.li/materials-a

\section{Phase formation through synthetic control: polymorphism in the sodium-ion solid electrolyte $\mathrm{Na}_{4} \mathrm{P}_{2} \mathrm{~S}_{6} \dagger$}

\author{
Tanja Scholz, (D) $\ddagger^{a}$ Christian Schneider, (D) $\ddagger^{a}$ Roland Eger, ${ }^{a}$ Viola Duppel, ${ }^{a}$ \\ Igor Moudrakovski, (D) ${ }^{a}$ Armin Schulz, ${ }^{a}$ Jürgen Nuss (D) and Bettina V. Lotsch (iD *ab
}

The development of all-solid-state sodium batteries for scalable energy storage solutions requires fast sodium conducting solid electrolytes. To fast-track their discovery, candidate materials need to be identified that are synthesized from abundant resources via cheap and green synthesis routes. Their ion conducting mechanism has to be understood and adapted to meet the stringent requirements for longterm operation in all-solid-state batteries. Here, structure and properties of the sodium hexathiohypodiphosphate $\mathrm{Na}_{4} \mathrm{P}_{2} \mathrm{~S}_{6}$ obtained by two different synthesis methods are compared: a solidstate reaction and a precipitation route from aqueous solution. Combined investigations using powder $X$-ray diffraction (PXRD), precession electron diffraction (PED), differential scanning calorimetry (DSC), solid-state nuclear magnetic resonance spectroscopy (ssNMR), and Raman spectroscopy reveal that the solid-state synthesized material is characterized by a $\mathrm{Na}^{+}$and vacancy disorder-driven enantiotropic phase transition at $160{ }^{\circ} \mathrm{C}\left(\alpha\right.$ - to $\left.\beta-\mathrm{Na}_{4} \mathrm{P}_{2} \mathrm{~S}_{6}\right)$, which is accompanied by a symmetry change of the $\mathrm{P}_{2} \mathrm{~S}_{6}{ }^{4-}$ anion. Precipitated $\mathrm{Na}_{4} \mathrm{P}_{2} \mathrm{~S}_{6}$ already crystallizes in a $\beta$-like polymorph at room temperature, likely assisted by inter- and intralayer defects. Bond-valence and nudged elastic band (NEB) calculations were employed to identify a low energy, $2 \mathrm{D}$ conduction network in $\beta-\mathrm{Na}_{4} \mathrm{P}_{2} \mathrm{~S}_{6}$, suggesting facile $2 \mathrm{D}$ longrange $\mathrm{Na}^{+}$diffusion. Electrochemical impedance spectroscopy reveals a higher ionic conductivity at room temperature in precipitated $\beta$-like $\mathrm{Na}_{4} \mathrm{P}_{2} \mathrm{~S}_{6}\left(2 \times 10^{-6} \mathrm{~S} \mathrm{~cm}^{-1}\right)$ compared to the solid-state $\alpha$ polymorph $\left(7 \times 10^{-7} \mathrm{~S} \mathrm{~cm}^{-1}\right)$. The activation energy is around $0.4 \mathrm{eV}$ for both materials. The findings highlight that even subtle structural changes can significantly impact the sodium-ion diffusion in solid electrolytes and at the same time reveal an intricate interplay between phase formation and synthetic control.

\section{Introduction}

All-solid-state batteries based on solid electrolytes as core components have emerged as potential alternatives to state-ofthe-art lithium ion batteries that have become indispensable in powering our modern-day society. Especially in the critical areas of electromobility and renewable energy storage where conventional concepts cannot keep up with the ever-growing energy requirements, solid-state batteries promise improved power and energy density as well as safety and versatile cell geometries. For some applications such as stationary, largescale energy storage where the critical geo-political abundance

\footnotetext{
${ }^{a}$ Max Planck Institute for Solid State Research, Heisenbergstraße 1, 70569 Stuttgart, Germany. E-mail: b.lotsch@fkf.mpg.de

${ }^{b}$ LMU Munich, Butenandstraße 5-13, 81377 Munich, Germany

$\dagger$ Electronic supplementary information (ESI) available. CSD 2031308. For ESI and crystallographic data in CIF or other electronic format see DOI: 10.1039/d0ta11008f

$\ddagger$ Contributed equally to this work.
}

and cost of lithium are the most pressing issues, rechargeable sodium-ion batteries promise to be a viable alternative. This has revitalized intense research on sodium-ion conducting materials for solid electrolytes. ${ }^{1-3}$ However, in order to increase the number of competitive $\mathrm{Na}^{+}$solid electrolytes, candidate materials need to be identified that are synthesized from abundant resources (e.g. sulphur and phosphorus) via cheap and green synthesis routes, and their ion conduction mechanisms need to be understood and adapted to meet the stringent requirements for long-term operation in all-solid-state batteries.

Historically, well-known $\mathrm{Na}^{+}$solid electrolytes are $\mathrm{Na}-\beta$ $\mathrm{Al}_{2} \mathrm{O}_{3}$ (ref. 4) and the NaSICON family 5 ,6 that both typically use operating temperatures of about $300{ }^{\circ} \mathrm{C}$ to provide sufficiently high ion mobilities. ${ }^{3}$ In the last years, superionic polyborates of closo-borate anions $\mathrm{B}_{n} \mathrm{H}_{n}{ }^{2-}$ such as $\mathrm{Na}_{2}\left(\mathrm{~B}_{12} \mathrm{H}_{12}\right)_{0.5}\left(\mathrm{~B}_{10} \mathrm{H}_{10}\right)_{0.5}$ have attracted much attention as they offer promising room temperature conductivities as high as $0.9 \mathrm{mS} \mathrm{cm}^{-1} .7,8$

A new direction in $\mathrm{Na}^{+}$solid electrolyte research opened up in 2012 when Hayashi et al. described the stabilization of the cubic $\beta$-sodium ortho-thiophosphate $\mathrm{Na}_{3} \mathrm{PS}_{4}$ phase in a "glass- 
ceramic" state at ambient temperature with an ionic conductivity of $0.2 \mathrm{mS} \mathrm{cm}^{-1}$ to $0.46 \mathrm{mS} \mathrm{cm}^{-1} \cdot{ }^{9-11}$ That is an improvement by two orders of magnitude compared to the thermodynamically stable tetragonal $\alpha-\mathrm{Na}_{3} \mathrm{PS}_{4}$ phase. ${ }^{12}$ Only recently, this compound hit yet another milestone when a second high temperature polymorph $(\gamma)$ was described as a plastic crystal. ${ }^{13}$ The potential of thiophosphates as a material class for solid electrolytes is reflected in numerous studies that were able to further improve the ionic conductivity by substitution of phosphorus or sulphur in tetrahedral $\mathrm{PS}_{4}{ }^{3-} \cdot{ }^{14-18}$ Structural expansion, changing the polarizability, and creating $\mathrm{Na}^{+}$interstitials and vacancies through iso- or aliovalent doping are common concepts to enhance ion mobility. $\mathrm{Na}_{2.9} \mathrm{P}_{0.9} \mathrm{~W}_{0.1} \mathrm{~S}_{4}$ and $\mathrm{Na}_{2.9} \mathrm{Sb}_{0.9} \mathrm{~W}_{0.1} \mathrm{~S}_{4}$ are the fastest ion conductors derived from the parent compound $\mathrm{Na}_{3} \mathrm{PS}_{4}$ known today with conductivities of $13 \mathrm{mS} \mathrm{cm}^{-1}$ and $41 \mathrm{mS} \mathrm{cm}^{-1}$, respectively. ${ }^{19,20}$

As portrayed by these works, the sodium thiophosphate family is a powerful material class for fast ion conduction and, more importantly, already proved functional in all-solid state batteries. ${ }^{9,10}$ Recently, Fritsch et al. studied the ionic conductivity and local structure of the sodium hexathiometadiphosphate $\mathrm{Na}_{2} \mathrm{P}_{2} \mathrm{~S}_{6}$ (ref. 21) with a conductivity of $10^{-8} \mathrm{~S} \mathrm{~cm}^{-1}$ in the amorphous material obtained by a ball milling synthesis compared to $10^{-11} \mathrm{~S} \mathrm{~cm}^{-1}$ in the crystalline compound. ${ }^{22}$ The enhanced conductivity in the amorphous materials arises from sodium disorder and single $\mathrm{PS}_{4}{ }^{3-}$ tetrahedra incorporated in addition to $\mathrm{P}_{2} \mathrm{~S}_{6}{ }^{2-}$. Another superionic sulfide-based electrolyte with thiophosphate and thiostannate anions is $\mathrm{Na}_{11} \mathrm{Sn}_{2} \mathrm{PS}_{12} \cdot{ }^{23,24}$ Its high conductivity of $4 \mathrm{mS} \mathrm{cm}^{-1}$ originates from significant intrinsic $\mathrm{Na}^{+}$vacancies and a large variety of alternative three-dimensional pathways with similar migration barriers along different directions.

Sodium hexathiohypodiphosphate $\mathrm{Na}_{4} \mathrm{P}_{2} \mathrm{~S}_{6}$, the compound discussed in this publication, was first mentioned in a study on precipitated $\mathrm{Na}_{4} \mathrm{P}_{2} \mathrm{~S}_{6} \cdot 6 \mathrm{H}_{2} \mathrm{O}$ as its dehydration product. ${ }^{25}$ The crystal structure was reported later by our group where $\mathrm{Na}_{4} \mathrm{P}_{2} \mathrm{~S}_{6}$ was obtained via a solid-state synthesis. ${ }^{21}$ The main characteristic of the monoclinic structure is a layered arrangement of $\mathrm{P}_{2} \mathrm{~S}_{6}{ }^{4-}$ anions in planes with an $[\mathrm{ABC}]$ stacking ( $c f$. Fig. 1a and ESI†). In these planes and between them are two crystallographically different sodium ions, coordinated octahedrally by sulphur atoms. The molecular axes of the $\mathrm{P}_{2} \mathrm{~S}_{6}{ }^{4-}$ anions are tilted by $4^{\circ}$ from the layer normal while they are parallel in related compounds like $\mathrm{FePS}_{3}$. The $\mathrm{P}_{2} \mathrm{~S}_{6}{ }^{4-}$ layer is reminiscent of a hexagonal pattern. This structure is unique among the alkali hexathiohypodiphosphates $\mathrm{A}_{4} \mathrm{P}_{2} \mathrm{~S}_{6}: \mathrm{Li}_{4} \mathrm{P}_{2} \mathrm{~S}_{6}$ is also a layered structure but with an $[\mathrm{AA}]$ stacking resulting in a different distribution of alkali ions between the layers, whereas $\mathrm{K}_{4} \mathrm{P}_{2} \mathrm{~S}_{6}$ and $\mathrm{Rb}_{4} \mathrm{P}_{2} \mathrm{~S}_{6}$ exhibit three-dimensional structures. ${ }^{21,26}$ Rush et al. modeled the $\mathrm{Na}^{+}$ion dynamics of $\mathrm{Na}_{4} \mathrm{P}_{2} \mathrm{~S}_{6}$ with DFT calculations and estimated a low activation energy of $E_{\mathrm{a}} \approx 0.4 \mathrm{eV}^{27} \mathrm{~A}$ more recent comprehensive DFT study of the same group emphasizes the potential of $\mathrm{Na}_{4} \mathrm{P}_{2} \mathrm{~S}_{6}$ as $\mathrm{Na}^{+}$ionic conductor, stresses the low activation energy of the material, and reveals considerable $\mathrm{Na}^{+}$ion motion in two dimensions in MD simulations. ${ }^{28}$ Indeed, for precipitated $\mathrm{Na}_{4} \mathrm{P}_{2} \mathrm{~S}_{6}$ (via the hydrate) Hood showed a room temperature conductivity of 3.4 $\times 10^{-6} \mathrm{~S} \mathrm{~cm}^{-1}$ with $E_{\mathrm{a}}=0.35 \mathrm{eV}$ and pointed out that rehydration and subsequent dehydration does not impact the electrochemical performance, making this compound more compliant with battery applications. ${ }^{29}$ Based on our study, we assume that $\mathrm{Na}_{4} \mathrm{P}_{2} \mathrm{~S}_{6}$ prepared by Hood is similar to our precipitated $\beta$-like samples.

In this paper, we compare the structure and properties of $\mathrm{Na}_{4} \mathrm{P}_{2} \mathrm{~S}_{6}$ obtained by different synthesis routes and describe a new high-temperature polymorph $(\beta)$ that has significant intrinsic $\mathrm{Na}^{+}$vacancies and forms above $160{ }^{\circ} \mathrm{C}$ when synthesized via a solid-state route according to ref. 21. Combined investigations using powder X-ray diffraction (PXRD), differential scanning calorimetry (DSC), precession electron diffraction (PED), solid-state nuclear magnetic resonance spectroscopy (ssNMR), and Raman spectroscopy reveal that precipitated $\mathrm{Na}_{4} \mathrm{P}_{2} \mathrm{~S}_{6}$ via solution synthesis ( $c f$. ref. 25), however, already crystallizes in a $\beta$-like polymorph at room temperature which is stabilized by subtle structural defects, e.g. stacking faults. A comprehensive mechanistic study based on bond valence energy landscape (BVEL) and nudged elastic band (NEB) calculations pinpoint how the ionic conductivity is influenced by structural changes upon the phase transition and the presence of $\mathrm{Na}^{+}$vacancies. Electrochemical impedance spectroscopy measurements portray precipitated $\beta$-like $\mathrm{Na}_{4} \mathrm{P}_{2} \mathrm{~S}_{6}$ as an ion conductor with a room-temperature conductivity of $2 \times$ $10^{-6} \mathrm{~S} \mathrm{~cm}^{-1}$ and an activation energy of $0.4 \mathrm{eV}$ while solid-state $\alpha-\mathrm{Na}_{4} \mathrm{P}_{2} \mathrm{~S}_{6}$ has a lower conductivity of $7 \times 10^{-7} \mathrm{~S} \mathrm{~cm}^{-1}$ with a similar activation energy.

\section{Results and discussion}

\section{Polymorphism in $\mathrm{Na}_{4} \mathrm{P}_{2} \mathrm{~S}_{6}$}

As a starting point to elucidate the phase formation and polymorphism of $\mathrm{Na}_{4} \mathrm{P}_{2} \mathrm{~S}_{6}$, we synthesized $\mathrm{Na}_{4} \mathrm{P}_{2} \mathrm{~S}_{6}$ via two alternative synthesis routes - a solid-state route ${ }^{21}$ and by precipitation from aqueous solution. ${ }^{25}$ The high-temperature behavior of the as-obtained materials was investigated by PXRD (Fig. 1b and c). For the solid-state thiophosphate a phase transition appears at around $200^{\circ} \mathrm{C}$ with a splitting of the reflection at $7^{\circ} 2 \theta\left(\mathrm{Mo} \mathrm{K} \alpha_{1}\right.$, indices (020) and (110)). The structure of this new hightemperature polymorph, dubbed $\beta-\mathrm{Na}_{4} \mathrm{P}_{2} \mathrm{~S}_{6}$, is closely related to the low-temperature polymorph and crystallizes in the same space group $C 2 / m$ (Fig. 1a). The phase transition is primarily characterized by the occupation of a new sodium position ( $\mathrm{Na} 3$, Wyckoff position $2 d$ ) at the expense of $\mathrm{Na} 2$. The $2 d$ position is an unoccupied, distorted $S_{6}$ octahedral void in the $\alpha$ phase's van der Waals gap. Therefore, the phase transition generates an exceptionally high amount of intrinsic $\mathrm{Na}^{+}$vacancies. Further, subtle structural changes such as in the distances and tilting of the $\mathrm{P}_{2} \mathrm{~S}_{6}{ }^{4-}$ anions occur, which we discuss in detail below. Recently, Li et al. computationally predicted the $2 d$ position to be the energetically most favorable interstitial site. ${ }^{28}$ Their MD simulations already suggest an involvement of this site in the $\mathrm{Na}^{+}$migration path, and we present here experimental proof for the occupation of the $\mathrm{Na} 3$ position at elevated temperatures. Empty voids are also present in the structure of $\mathrm{Li}_{4} \mathrm{P}_{2} \mathrm{~S}_{6}$, but they 
a
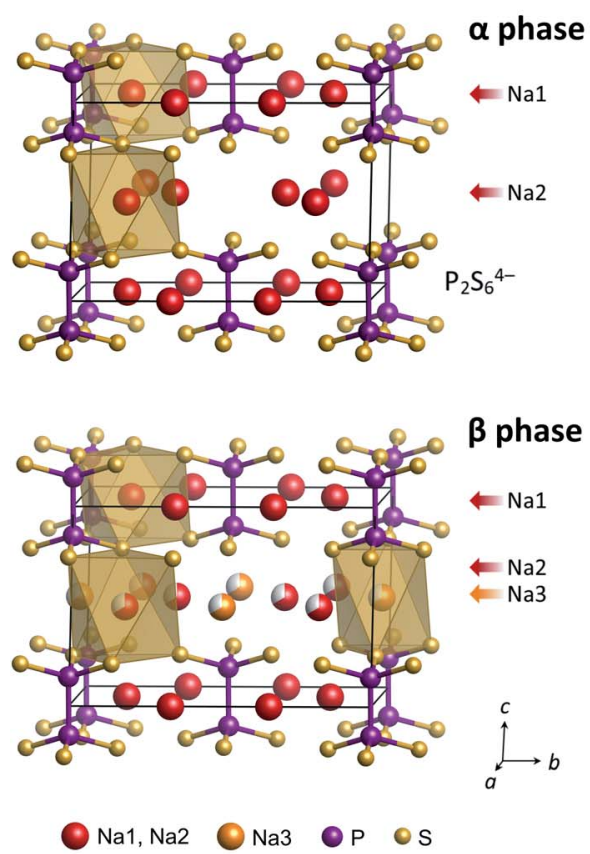

b

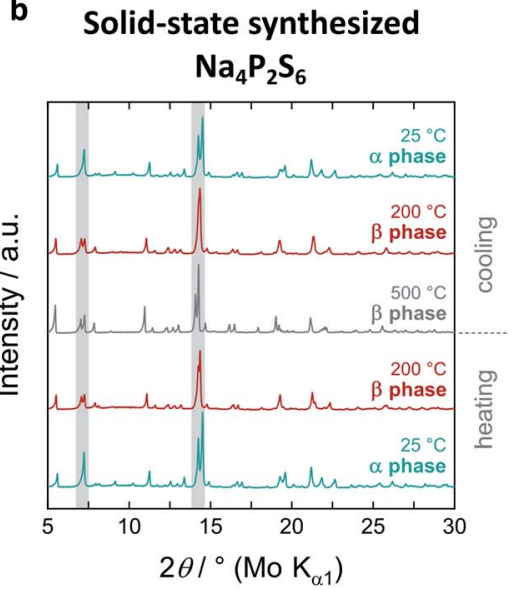

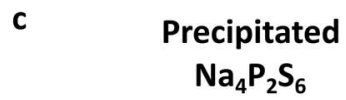

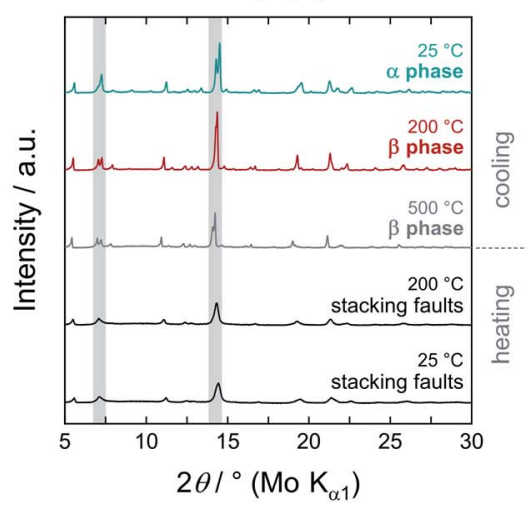

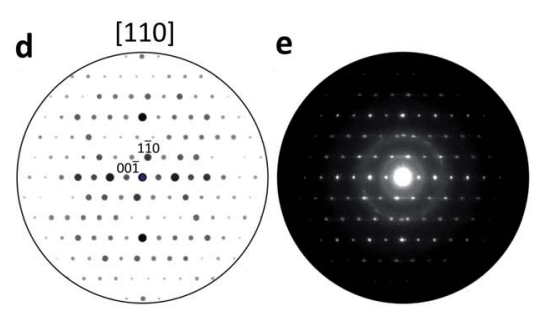

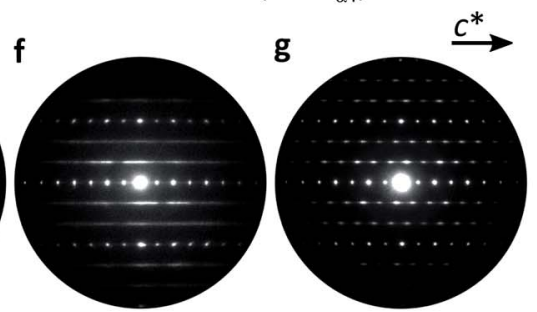

Fig. 1 (a) Crystal structure of solid-state synthesized $\mathrm{Na}_{4} \mathrm{P}_{2} \mathrm{~S}_{6}$ in the monoclinic space group C2/m (no. 12) at room temperature ( $\alpha$ ) and high temperature $(\beta)$ with a layered arrangement of $\mathrm{P}_{2} \mathrm{~S}_{6}{ }^{4-}$ (P: purple, S: yellow). Sodium atoms (red and orange) are coordinated octahedrally by sulphur atoms. (b and c) HT-XRD patterns of solid-state and precipitated $\mathrm{Na}_{4} \mathrm{P}_{2} \mathrm{~S}_{6}$ with shaded regions to differentiate between the polymorphs. (d) Simulated PED pattern in comparison to measured PED patterns of (e) sublimed (representing the solid-state material), ( $f$ ) precipitated, and (g) annealed $\mathrm{Na}_{4} \mathrm{P}_{2} \mathrm{~S}_{6}$.

are capped by the $\mathrm{P}_{2} \mathrm{~S}_{6}{ }^{4-}$ anion and their occupation is energetically much more unfavorable. ${ }^{26} \beta-\mathrm{Na}_{4} \mathrm{P}_{2} \mathrm{~S}_{6}$ is still observed at $500{ }^{\circ} \mathrm{C}$ and the $\alpha-\beta$ transition is reversible upon cooling.

The precipitation route also gives a crystalline $\mathrm{Na}_{4} \mathrm{P}_{2} \mathrm{~S}_{6}$ solid that is, however, characterized by broad reflections in the PXRD pattern that do not allow for the $\alpha-\beta$ differentiation. Upon heating no phase transition can be tracked by PXRD until about $500{ }^{\circ} \mathrm{C}$ where sharp reflections of the $\beta$ phase occur. Cooling back to room temperature, however, the $\alpha$ phase develops into the annealed material. To unravel the differences of solid-state, precipitated, and annealed $\mathrm{Na}_{4} \mathrm{P}_{2} \mathrm{~S}_{6}$, we recorded PED patterns that are presented in Fig. 1d-g. Note that the PED pattern of the solid-state $\mathrm{Na}_{4} \mathrm{P}_{2} \mathrm{~S}_{6}$ was obtained from a sample that was additionally sublimed at $750{ }^{\circ} \mathrm{C}$, since the recording of the desired direction was not feasible in the raw solid-state reaction product. This sample shows sharp reflections that are in agreement with those of a simulated pattern along the [110] zone axis. Contrary, diffuse scattering occurs as streaks in precipitated $\mathrm{Na}_{4} \mathrm{P}_{2} \mathrm{~S}_{6}$. This indicates the presence of planar defects, which are located in the $c$ direction, the stacking direction of the crystal structure. These defects modulate the layer distance and can stem from e.g. stacking faults, residual crystal water, and/or thiophosphate disorder. The remaining sharp reflections agree with the simulated pattern. The defects are largely healed in the annealed sample where the diffuse scattering is reduced in intensity and reflections become visible and are comparable to the solid-state product.
With the structural differences of the two synthesized samples roughly understood, DSC measurements, ssNMR experiments, and Raman spectroscopy were carried out to follow the $\alpha-\beta$ phase transition and elucidate the subtle structural differences.

Differential scanning calorimetry. DSC curves were recorded between 80 and $300{ }^{\circ} \mathrm{C}$ in three consecutive runs and are illustrated in Fig. 2a-c. Upon heating, solid-state $\alpha-\mathrm{Na}_{4} \mathrm{P}_{2} \mathrm{~S}_{6}$ shows an endothermic signal composed of two convoluted peaks, a small one followed by a larger peak. The latter has an onset temperature of $160^{\circ} \mathrm{C}$. The combined exchanged heat of both peaks is $10 \pm 1 \mathrm{~J} \mathrm{~g}^{-1}$. Cooling down the sample, the corresponding $\beta$ to $\alpha$ transition occurs as a sharp exothermic peak with an onset of $160{ }^{\circ} \mathrm{C}$. Again two peaks are convoluted. However, upon cooling the larger peak appears first. The measured thermogram is completely reversible upon cycling, suggesting an enantiotropic phase transition. Since thermal effects could stem from rearrangements of anions or reshuffling of site occupancies to allow the structure to relax into a lower energy polymorph, we attribute the signals in the solid-state material to be of such a structural transition.

Precipitated $\mathrm{Na}_{4} \mathrm{P}_{2} \mathrm{~S}_{6}$ shows a very different DSC thermogram, in fact, no sharp exothermic nor endothermic signal can be measured, suggesting that the phase transition is suppressed and that a $\beta$-like structure is stabilized already at room temperature. This observation holds for multiple cycles around the expected transition temperature. 


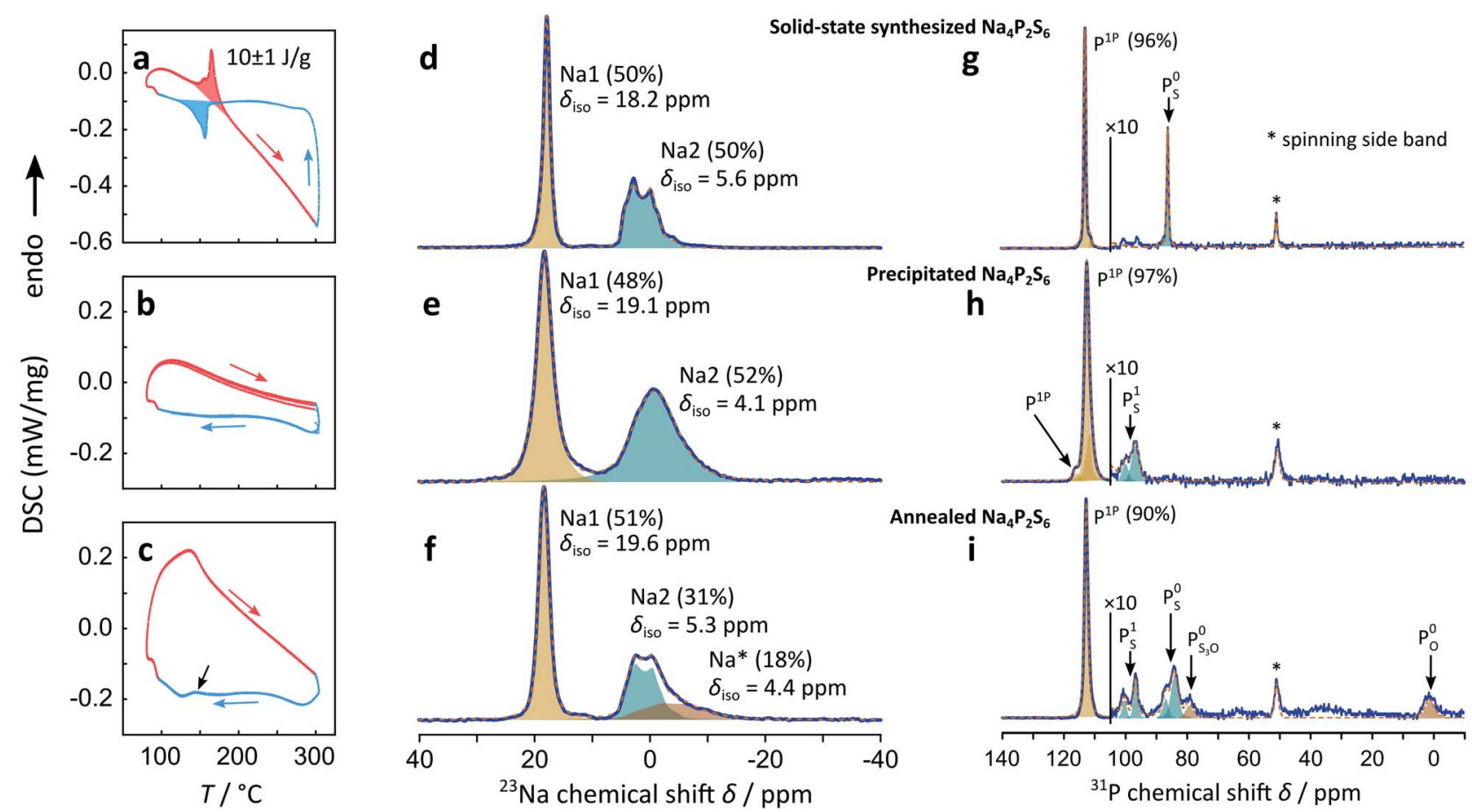

Fig. 2 DSC curves of (a) solid-state $\alpha / \beta$, (b) precipitated $\beta$-like, and (c) annealed $\mathrm{Na}_{4} \mathrm{P}_{2} \mathrm{~S}_{6}$. The three-times consecutively measured heating and cooling scans are depicted in red and blue, respectively. The initial heating scan was discarded. ${ }^{23} \mathrm{Na}(\mathrm{d}-\mathrm{f})$ and ${ }^{31} \mathrm{P}(\mathrm{g}-\mathrm{i}) \mathrm{MAS}$ ssNMR spectra of $\mathrm{Na}_{4} \mathrm{P}_{2} \mathrm{~S}_{6}$ at room temperature. The measured and calculated spectra are depicted as blue and orange lines, respectively. Fitted peaks are displayed as half-transparent peak areas of different color. The integral ratio is displayed as numbers in parentheses. For the ${ }^{31} \mathrm{P}-\mathrm{NMR}$ spectra high field peaks next to the peak for $\mathrm{P}_{2} \mathrm{~S}_{6}{ }^{4-}$ are 10 -fold magnified.

In the above diffraction experiments annealed $\mathrm{Na}_{4} \mathrm{P}_{2} \mathrm{~S}_{6}$ appears "healed" from stacking faults, however, its DSC signal shows no sharp peak around the temperature where we observe a signal for solid-state $\mathrm{Na}_{4} \mathrm{P}_{2} \mathrm{~S}_{6}$, but rather a sharp kink of the DSC signal around $150{ }^{\circ} \mathrm{C}$, compared to the precipitated sample shown in Fig. 2b. Cooling the sample, a smeared out thermal event appears at around $140{ }^{\circ} \mathrm{C}$, indicated by a black arrow in Fig. 2c. Since this broad peak is absent in the precipitated sample, we assume it to originate from a sluggish phase transition with a low exchanged heat. This suggests a material with structural properties midway between those of the solid-state and precipitated samples.

Solid-state nuclear magnetic resonance spectroscopy. sSNMR experiments were conducted at room temperature to elucidate the local environment of sodium by ${ }^{23} \mathrm{Na}$ magic angle spinning (MAS) NMR; the anionic thiophosphate sublattice as well as (thio-)phosphate impurities are revealed by ${ }^{31} \mathrm{P}$ MAS NMR. The spectra of the solid-state $\alpha$, precipitated $\beta$-like, and annealed $\mathrm{Na}_{4} \mathrm{P}_{2} \mathrm{~S}_{6}$ are depicted in Fig. $2 \mathrm{~d}-\mathrm{i}$. The fits of the ${ }^{23} \mathrm{Na}$ MAS NMR spectra yield two signals for both the solid-state and the precipitated sample, and three signals for the annealed $\mathrm{Na}_{4} \mathrm{P}_{2} \mathrm{~S}_{6}$. Two different sodium positions of equal occupation are expected from the crystal structure of solid-state synthesized $\alpha-\mathrm{Na}_{4} \mathrm{P}_{2} \mathrm{~S}_{6} .{ }^{21}$ The fitted integral ratio of $50 \%$ (Na1) to $50 \%$ (Na2) for the solid-state material, therefore, reflects the previously reported structure. ${ }^{21}$ The two resonance peaks at $\delta_{\text {iso }}=$ $18.2 \mathrm{ppm}$ and $\delta_{\text {iso }}=5.6 \mathrm{ppm}$ were fitted with a model accounting for second order quadrupolar line broadening $(I=$
$3 / 2{ }^{23} \mathrm{Na}$ nucleus), observed especially for the signal at $\delta_{\text {iso }}=$ $5.6 \mathrm{ppm}$. We assign these two resonances to the crystallographic positions $\mathrm{Na}$, residing in a symmetrical environment in the $\mathrm{P}_{2} \mathrm{~S}_{6}{ }^{4-}$ layer, and the less symmetrically coordinated Na2 site, indicated by the larger quadrupolar coupling constant, in the interlayer space, respectively ( $c f$. Fig. 1a). For the discussion of the ${ }^{31} \mathrm{P}$ spectra we make use of the short range order (SRO) notation for phosphate compounds as described by Kmiec et al. $^{30}$ Besides the main resonance at $\delta_{\text {iso }}=112.9 \mathrm{ppm}\left(\mathrm{P}_{2} \mathrm{~S}_{6}{ }^{4-}\right.$, $\left.\mathrm{P}^{1 \mathrm{P}}\right)$, the ${ }^{31} \mathrm{P}$ MAS spectrum of solid-state $\mathrm{Na}_{4} \mathrm{P}_{2} \mathrm{~S}_{6}$ reveals one small additional signal at $\delta_{\text {iso }}=86.7 \mathrm{ppm}$. We attribute this to $\mathrm{Na}_{3} \mathrm{PS}_{4}$ impurities as this chemical shift is characteristic for the ortho-thiophosphate anion $\mathrm{PS}_{4}{ }^{3-}\left(\mathrm{P}_{\mathrm{S}}^{0}\right)$.

Comparing the ${ }^{23} \mathrm{Na}$ MAS spectrum of precipitated $\beta$-like with solid-state $\alpha-\mathrm{Na}_{4} \mathrm{P}_{2} \mathrm{~S}_{6}$ there is one notable difference: the resonance peaks for $\mathrm{Na} 1$ and $\mathrm{Na} 2$ are clearly broader for the precipitated sample, indicating a more disordered material on the local or long-range scale (e.g. differences in the local $\mathrm{Na}$ environment, stacking faults, etc.). This observation is in line with the TEM study that was performed on sublimed and crude precipitated $\mathrm{Na}_{4} \mathrm{P}_{2} \mathrm{~S}_{6}$. The integral ratio of $48 \% \mathrm{Na} 1$ to $52 \% \mathrm{Na} 2$ is close to the expected half/half distribution of interlayer and intralayer sodium. The ${ }^{31} \mathrm{P}$ spectrum of precipitated $\mathrm{Na}_{4} \mathrm{P}_{2} \mathrm{~S}_{6}$ shows the resonance peak of $\mathrm{P}^{1 \mathrm{P}}$ in addition to two smaller signals with a similar chemical shift. We conclude that the higher disorder produced by the precipitation route leads to slightly different chemical environments not only for the $\mathrm{Na}^{+}$, but also for the $\mathrm{P}_{2} \mathrm{~S}_{6}{ }^{4-}$ anion, which is displayed in the three 
different $\mathrm{P}^{1 \mathrm{P}}$ resonances. The precipitation route also leads to a small impurity, which is different from the one observed for the solid-state synthesis in the studied batch of material. The chemical shift of around $\delta_{\text {iso }}=90-100 \mathrm{ppm}$ portends a side phase containing $\mathrm{P}_{\mathrm{S}}{ }^{1} \mathrm{SRO}$ units like in $\mathrm{Na}_{4} \mathrm{P}_{2} \mathrm{~S}_{7}$.

Annealing the precipitated $\mathrm{Na}_{4} \mathrm{P}_{2} \mathrm{~S}_{6}$ at $500{ }^{\circ} \mathrm{C}$ introduces a new ${ }^{23} \mathrm{Na}$ signal as a high-field shifted tail to $\mathrm{Na} 2$, in addition to low-field shifting the chemical shifts compared to the pristine sample. The integral ratio of $51 \%$ for the Na1 signal remains close to the expected $50 \%$ for this position, whereas the other resonance intensity is shared by Na2 (31\%) and the new $\mathrm{Na}^{*}(18 \%)$ signal. The latter signal broadens significantly and is high-field shifted compared to $\mathrm{Na} 2$, while the Na1 and $\mathrm{Na} 2$ signals show a smaller FWHM, comparable to the values found for the solid-state synthesized sample, indicating a gain in (long range) order upon annealing. The fact that for the annealed sample a third signal with a chemical shift close to the Na2 resonance is present, speaks yet again for a material in between the solid-state and precipitated $\mathrm{Na}_{4} \mathrm{P}_{2} \mathrm{~S}_{6}$. Note that also additional resonances arise in the ${ }^{31} \mathrm{P}$ MAS spectrum upon annealing the material. We assign these signals to a variety of thio-, thio/oxo- and oxo-phosphate impurities ${ }^{30}$ (about 10\% compared to $3 \%$ side phase in the precipitated sample). The main ${ }^{31} \mathrm{P}$ signal $\left(\delta_{\text {iso }}=112.8 \mathrm{ppm}\right)$ shows a smaller FWHM and no visible distribution of chemical shifts after annealing the sample.

To summarize, the solid-state synthesis yields the purest material, although a $\mathrm{Na}_{3} \mathrm{PS}_{4}$ side phase is present and difficult to avoid. Preparing $\mathrm{Na}_{4} \mathrm{P}_{2} \mathrm{~S}_{6}$ from solution holds the advantage of an easier synthesis but comes at the cost of higher disorder in addition to a side phase. Assisted by these defects, the precipitated material crystallizes in a $\beta$-like polymorph below the $\alpha-$ $\beta$ phase transition temperature. The subsequent annealing "heals" some degree of disorder, however, at the same time leads to the formation of additional side phases by presumably hydrolytic decomposition. Rapid cooling of the solid-state synthesized and annealed $\mathrm{Na}_{4} \mathrm{P}_{2} \mathrm{~S}_{6}$ from a temperature well above the transition point yields solely the $\alpha$ phase.

Raman spectroscopy. Raman spectra give access to the symmetry of the $\mathrm{P}_{2} \mathrm{~S}_{6}{ }^{4-}$ anion that is known to either exist in the low symmetric $C_{2 \mathrm{~h}}$ or the highly symmetric, ethane-like $D_{3 \mathrm{~d}}$ configuration ( $c f$. ESI $\dagger$ for details). Selected Raman spectra at different temperatures are shown in Fig. 3 for an $\alpha-\mathrm{Na}_{4} \mathrm{P}_{2} \mathrm{~S}_{6}$ single crystal obtained by the solid-state synthesis and precipitated $\beta$-like $\mathrm{Na}_{4} \mathrm{P}_{2} \mathrm{~S}_{6}$ powder. For a detailed summary of Raman band positions and their assignments to individual modes refer to the ESI. $\dagger$ At room temperature the Raman spectrum of solidstate $\mathrm{Na}_{4} \mathrm{P}_{2} \mathrm{~S}_{6}$ shows at least eleven peaks, of which six can be assigned to bending and stretching modes of the $\mathrm{P}_{2} \mathrm{~S}_{6}{ }^{4-}$ anion (marked as shaded regions). Here, the anion resembles its molecular anion with $C_{2 \mathrm{~h}}$ point symmetry. The remaining bands in the fingerprint region are assigned to lattice vibrations. Going above the $\alpha-\beta$ phase transition $\left(200^{\circ} \mathrm{C}\right)$ the Raman spectra suggest a change in symmetry to the highly symmetrical $D_{3 \mathrm{~d}}$ configuration. The modes at 257 and $274 \mathrm{~cm}^{-1}$ and at $574 \mathrm{~cm}^{-1}$ (two convoluted modes at lower temperature) degenerate to two modes of the type $\mathrm{E}_{\mathrm{g}}$. The strongest band centered at $379 \mathrm{~cm}^{-1}$, representing the characteristic P-P
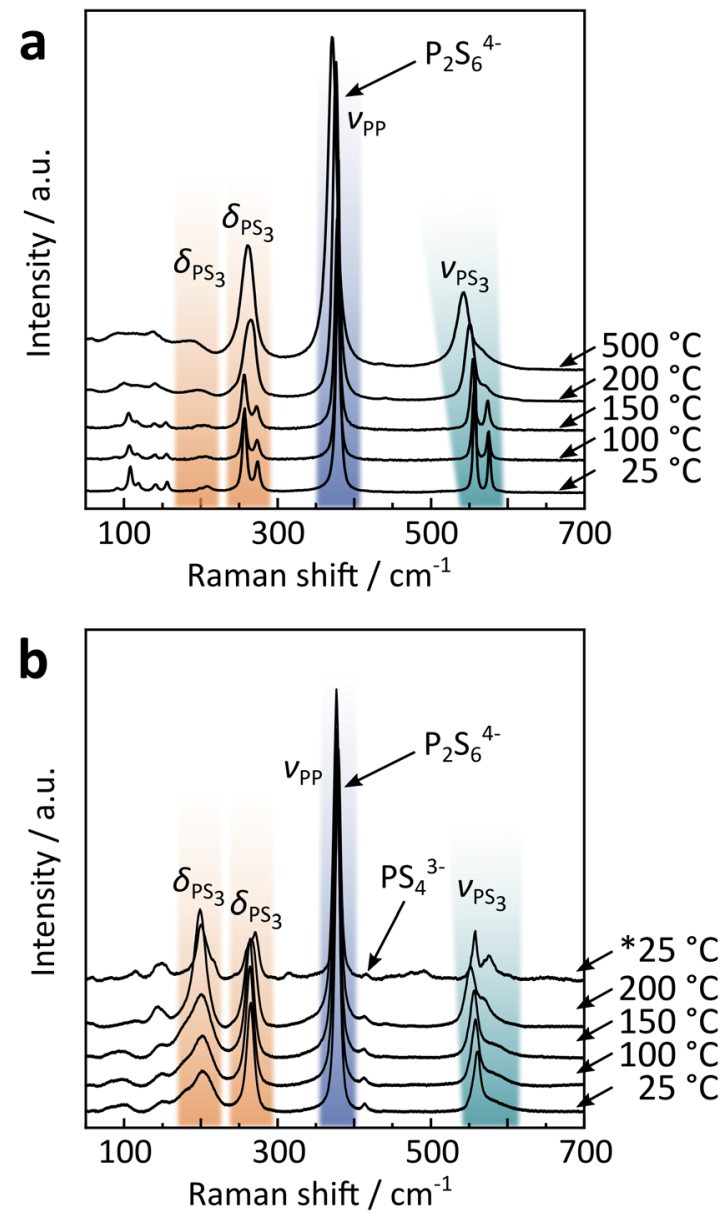

Fig. 3 Temperature dependent Raman spectra of (a) solid-state $\alpha$ / $\beta$ and (b) precipitated $\beta$-like $\mathrm{Na}_{4} \mathrm{P}_{2} \mathrm{~S}_{6}$. The asterisk indicates that the spectrum was recorded after cooling down the sample from $200^{\circ} \mathrm{C}$. A full assignment of Raman modes for $\mathrm{Na}_{4} \mathrm{P}_{2} \mathrm{~S}_{6}$ can be found in Table $\mathrm{S} 9$ in the ESI. $\dagger$

stretching mode, is persistent over the entire measured temperature range. Only a minor signal at around $420 \mathrm{~cm}^{-1}$ is observed at $500{ }^{\circ} \mathrm{C}$, hinting at a possible appearance of orthothiophosphates at elevated temperatures.

Contrary to the solid-state sample, precipitated $\mathrm{Na}_{4} \mathrm{P}_{2} \mathrm{~S}_{6}$ reveals a $\mathrm{P}_{2} \mathrm{~S}_{6}{ }^{4-}$ anion with $D_{3 \mathrm{~d}}$ symmetry already at room temperature, further supporting the proposition it is a $\beta$-like polymorph. Here, the $\mathrm{PS}_{3}$ deformation mode is observed around $200 \mathrm{~cm}^{-1}$ with significant intensity that is less pronounced in the single crystal solid-state $\mathrm{Na}_{4} \mathrm{P}_{2} \mathrm{~S}_{6}$. Additional Raman measurements on ground solid-state $\mathrm{Na}_{4} \mathrm{P}_{2} \mathrm{~S}_{6}$ show, however, similar intensities compared to the precipitated product, suggesting the orientation of the single crystal to be the reason for the low intensity of the deformation mode. We only measured up to $200{ }^{\circ} \mathrm{C}$, a temperature well above the $\alpha$ $\beta$ phase transition temperature in the solid-state material, but lower than the annealing temperature for precipitated $\mathrm{Na}_{4} \mathrm{P}_{2} \mathrm{~S}_{6}$ (observed at approx. $500^{\circ} \mathrm{C}$ according to XRD results, $c f$. Fig. 1c) to avoid the formation of side phases and to stay within the $\beta$ like polymorph. However, upon cooling the material already 
show a splitting of the modes as for the $\alpha$ polymorph, suggesting the beginning of annealing and "healing" from (stacking) faults of the precipitated sample already at temperatures below $500{ }^{\circ} \mathrm{C}$.

Structural changes of the phase transition. To gain deeper insight into the structural changes of the $\alpha-\beta$ transition, Rietveld refinements of a series of HT-XRDs (between $20^{\circ} \mathrm{C}$ and 300 $\left.{ }^{\circ} \mathrm{C}\right)$ were evaluated. The manuscript refers to the solid-state $\mathrm{Na}_{4} \mathrm{P}_{2} \mathrm{~S}_{6}$, but the same analysis for the annealed $\mathrm{Na}_{4} \mathrm{P}_{2} \mathrm{~S}_{6}$ (with some amorphous side phase as informed from NMR) is included in the ESI. $\dagger$ As already mentioned above, the main feature of the $\beta$ polymorph is the new sodium position Na3 that populates during the phase transition. As Fig. 4a illustrates, this occurs at the expense of $\mathrm{Na} 2$ until both sites are equally occupied by $2 / 3$ (remember the different multiplicities of $4 h$ and $2 d$ ). This is an exceptionally high amount of intrinsic $\mathrm{Na}^{+}$vacancies $(33 \%)$ in an ion conducting material. The refined occupation of
$\mathrm{Na} 3$ at room temperature varies from $0 \%$ to $11 \pm 4 \%$. Furthermore, we found a correlation of the quality of the prepared batch and the refined Na3 occupation, where samples with less side phase can be refined to a lower Na3 occupation. The Rietveld refinements further confirm the reversibility of the phase transition with only a slight shift for the very first heating process, consistent with the DSC measurements. To analyze the subtleties of the occupation of $\mathrm{Na} 2$ and $\mathrm{Na} 3$, the phase transition was additionally examined in a single crystal with single crystal X-ray diffraction at room temperature, subsequently at $227^{\circ} \mathrm{C}$, and again at room temperature. Here, the occupation of $\mathrm{Na} 3$ is completely reversible from zero (due to the absence of a side phase) to $2 / 3$ and again to zero ( $c f$. ESI $\dagger$ for single crystal data).

Fig. $4 \mathrm{~b}$ displays the volume of the unit cell that changes discontinuously $(+0.6 \%)$ as expected for a first order phase transition. Please refer to the ESI $\dagger$ for temperature dependency
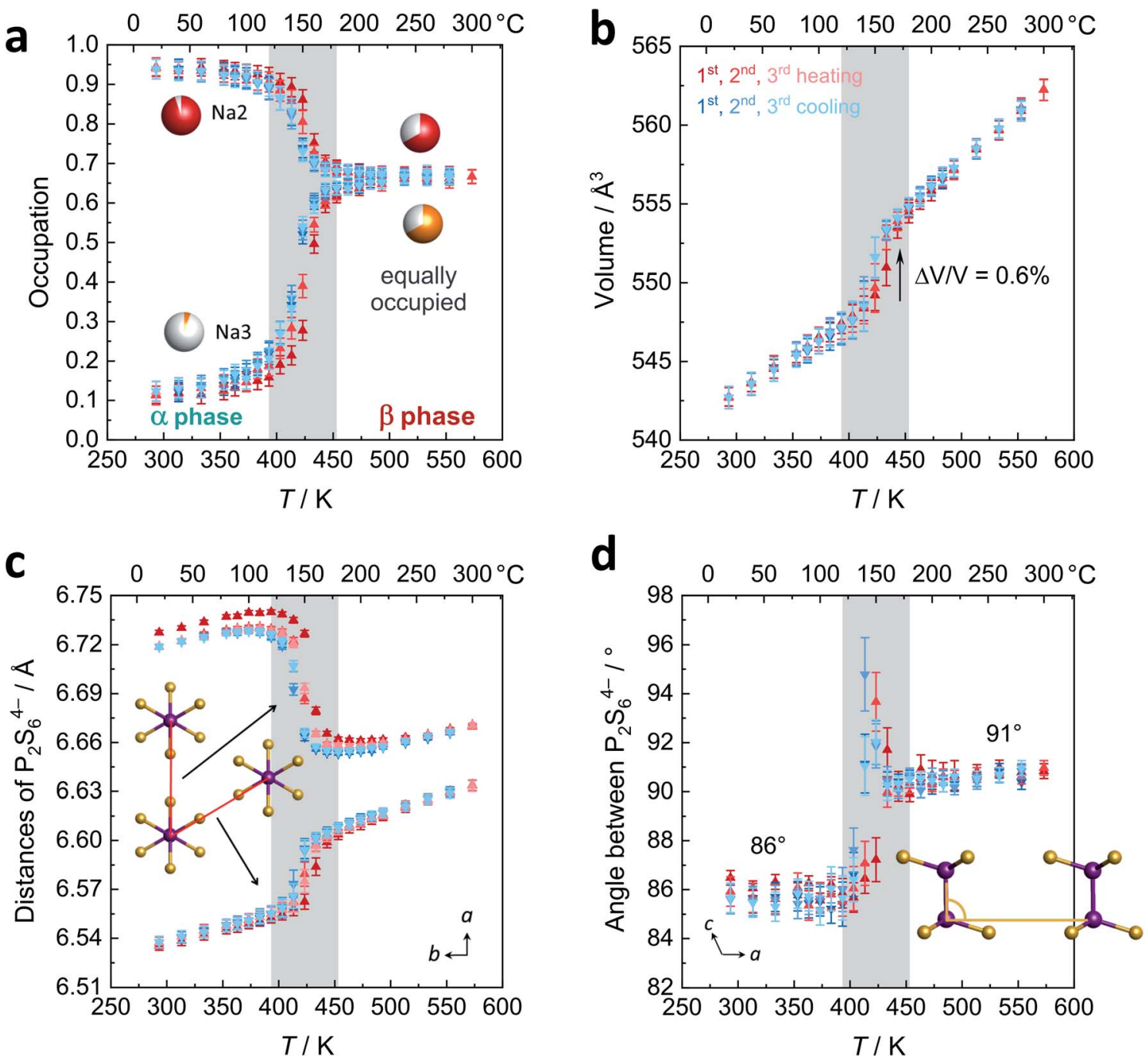

Fig. 4 Results of the Rietveld refinements for the $\alpha-\beta$ phase transition upon heating (red data points) and cooling (blue data points) for the first three cycles (color code from dark to light with increasing cycle number). (a) Occupation of the sodium positions Na2 and Na3 between the $\mathrm{P}_{2} \mathrm{~S}_{6}{ }^{4-}$ layers. (b) Volume change with temperature. (c) Distances of the $\mathrm{P}_{2} \mathrm{~S}_{6}{ }^{4-}$ anions as a measure for the hexagonality of the layer. (d) Tilting of neighboring $\mathrm{P}_{2} \mathrm{~S}_{6}{ }^{4-}$ anions in a direction expressed as the $\mathrm{P}-\mathrm{P}-\mathrm{P}_{\text {neighbor }}$ angle. 
of $a, b, c$, and $\beta$. The thermal expansion of $\beta-\mathrm{Na}_{4} \mathrm{P}_{2} \mathrm{~S}_{6}$ is higher than for the $\alpha$ polymorph with expansion coefficients of $6.2 \times$ $10^{-6} \mathrm{~K}^{-1}$ and $4.5 \times 10^{-6} \mathrm{~K}^{-1}$, respectively. Given these values, both belong in the group of intermediate expanding materials. ${ }^{31}$ Considering the structural changes during the phase transition, an interesting question is whether for $\beta-\mathrm{Na}_{4} \mathrm{P}_{2} \mathrm{~S}_{6}$ the $\mathrm{P}_{2} \mathrm{~S}_{6}{ }^{4-}$ layers now resemble a hexagonal pattern more closely. To this end, we evaluated the two relevant distances of the $\mathrm{P}_{2} \mathrm{~S}_{6}{ }^{4-}$ units (defined as the middle of the $\mathrm{P}-\mathrm{P}$ dumbbell) as shown in Fig. 4c. The distances indeed approach each other after the phase transition $\left(6.61 / 6.66 \AA\right.$ at $\left.200{ }^{\circ} \mathrm{C}\right)$ as compared to the $\alpha$ phase $\left(6.54 / 6.72 \AA\right.$ at $\left.20^{\circ} \mathrm{C}\right)$. Nevertheless, they are still unequal in the $\beta-\mathrm{Na}_{4} \mathrm{P}_{2} \mathrm{~S}_{6}$ polymorph and the symmetry thus is not hexagonal. Furthermore, we were interested in the unique tilting of $\mathrm{P}_{2} \mathrm{~S}_{6}{ }^{4-}$ along the stacking direction, measured by the P-P-P angle of two neighboring anions in $a$ direction. This angle changes from $86^{\circ}$ in $\alpha$ to $91^{\circ}$ in $\beta-\mathrm{Na}_{4} \mathrm{P}_{2} \mathrm{~S}_{6}$ (Fig. $4 \mathrm{~d}$ ). At the phase transition it was even refined to more extreme values of up to $95^{\circ}$, presumably reflecting the $\mathrm{Na}^{+}$rearrangement and changes in unit cell dimensions.

\section{Sodium-ion conductivity}

Pathways of $\mathrm{Na}^{+}$conductivity. To investigate possible $\mathrm{Na}^{+}$ migration pathways and the effect of the $\alpha-\beta$ phase transition on the $\mathrm{Na}^{+}$trajectory, the bond valence energy landscape (BVEL) was calculated for both $\mathrm{Na}_{4} \mathrm{P}_{2} \mathrm{~S}_{6}$ polymorphs. Fig. 5a illustrates the iso-energy surface in the $\mathrm{Na} 2 / \mathrm{Na} 3$ layer of $\alpha-\mathrm{Na}_{4} \mathrm{P}_{2} \mathrm{~S}_{6}$ with increasing energy from left to right. At low potential energy, the BVEL reveals two possible sites that are indeed the Wyckoff positions $4 h(\mathrm{Na} 2)$ and $2 d(\mathrm{Na} 3)$. The $\mathrm{Na} 2$ position is $0.2 \mathrm{eV}$ lower in potential energy than the Na3 position. This finding is in line with sodium solely occupying the Na2 position in the ground state and populating $\mathrm{Na} 3$ at higher temperature, hence higher energy. Increasing the energy further, an interstitial site of tetrahedral symmetry appears as a local minimum that connects both low energy octahedrally coordinated sodium sites through two transition states. Note that this pathway covers only three sodium sites and is not forming a long-range conduction pathway across the unit cells ( $c f .2 .1 \mathrm{eV})$. We introduce the word triple for this $\mathrm{Na} 2-\mathrm{Na} 3-\mathrm{Na} 2$ island for later discussion. However, since an extended pathway is crucial for long-range ion diffusion, an additional energy of $0.9 \mathrm{eV}$ is necessary to interconnect the triples ( $c f$. Fig. 5b and $\mathrm{S} 11 \dagger$ ). Overall, the migration energy for $\mathrm{Na}^{+}$in this two-dimensional network in the $a b$ plane is calculated to be about $3.0 \mathrm{eV}$, a very high value for an ion conducting material. Note, however, that calculations based on the bond valence (BV) approach are known to overestimate migration barriers, as the BV method is based on calculating potential energies at fixed grid points of a "stiff" lattice. Relaxation of the anionic sublattice during ion migration is not part of this method, hence barriers are higher than one would measure in a real sample. Sodium ions Na1 occupying the octahedral sites within the $\mathrm{P}_{2} \mathrm{~S}_{6}{ }^{4-}$ layers are not part of this $\mathrm{Na}^{+}$network, since they experience a much stronger interaction with the close-by $\mathrm{P}_{2} \mathrm{~S}_{6}{ }^{4-}$ dumbbells, narrowing possible channels for ion migration ( $c f$. Fig. $5 c$ ). We thus expect these Na1 sites to be rather immobile, rendering ion transport in this material essentially 2D. For comparison, the BVEL of $\beta$ $\mathrm{Na}_{4} \mathrm{P}_{2} \mathrm{~S}_{6}$ is also drawn in Fig. 5c. The structural changes of the phase transition only have a minimal impact on the intra-triple $\mathrm{Na} 2-\mathrm{Na} 3-\mathrm{Na} 2$ diffusion ('), but significantly reduce the energy barrier for the important long-ranged inter-triple sodium diffusion (") from $3.0 \mathrm{eV}$ to about $2.3 \mathrm{eV}$. On this account, we expect the phase transition to significantly affect the $\mathrm{Na}^{+}$ diffusion. The BVEL method, however, does not consider local atomic orderings and does not account for the important influence of the vacancies in this material.

A more local approach, namely, nudged elastic band (NEB) calculations on the basis of DFT were carried out to obtain a complimentary view on the $\mathrm{Na}^{+}$migration. In the calculations, we neither attempted a full treatment of disorder nor accounted for correlated ion motion. The reader is referred to the experimental section for simplifications we made and reasons for it. Therefore, the following considerations provide a qualitative rather than a quantitative understanding. Both $\alpha$ - and $\beta$ $\mathrm{Na}_{4} \mathrm{P}_{2} \mathrm{~S}_{6}$ were studied for comparison. Further, we anticipated the importance of the local environment and re-used the classification for migration scenarios from the bond valence study: $\mathrm{Na}^{\prime} \rightleftharpoons \mathrm{Na} 3^{\prime}$ intra-triple diffusion ( $\left.{ }^{\prime}\right)$ and inter-triple diffusion $\left({ }^{\prime \prime}\right)$, whereby the latter was divided in $\mathrm{Na} 2{ }^{\prime} \rightleftharpoons \mathrm{Na}^{\prime \prime}$ and $\mathrm{Na}^{\prime} \rightleftharpoons$ $\mathrm{Na}^{\prime \prime}$ diffusion. For all three classes we picked exemplary sodium ion-vacancy orderings and migration scenarios along the established tetrahedral voids and tried to keep the ordering of $\mathrm{Na}^{+}$ions that are not involved in the jump as comparable as possible for the different scenarios. Li et al. ${ }^{28}$ considered in their recent study only the $\mathrm{Na} 2^{\prime} \rightleftharpoons \mathrm{Na} 2^{\prime \prime}$ diffusion in $\alpha-\mathrm{Na}_{4} \mathrm{P}_{2} \mathrm{~S}_{6}$ along the direct connection of the sites and not the tetrahedral interstitials. Fig. 6 displays the chosen scenarios and results of the NEB calculations.

Scenario 1 is the $\mathrm{Na}^{+}$migration from a Na2 site to an unoccupied $\mathrm{Na} 3$ site within a triple $\left(\mathrm{Na}^{\prime} \rightarrow \mathrm{Na}^{\prime}\right)$ along the BVEL pathway and, therefore, stands for the first step in the $\alpha$ to $\beta$ phase transition. Contrary to the BVEL, the tetrahedral interstitial is a maximum in the energy curve with $E_{\text {mig }}=1.1 \mathrm{eV}$ for both $\alpha$ - and $\beta-\mathrm{Na}_{4} \mathrm{P}_{2} \mathrm{~S}_{6}$. This barrier is overestimated as a consequence of our DFT simplifications; this assumption is consistent with the fact that the phase transition already happens at considerably low thermal energy $\left(160^{\circ} \mathrm{C}\right)$. After the migration, the energy of the system has significantly increased and this flattens the energy landscape for the ensuing ion motion. Scenario 2, which is a consecutive $\mathrm{Na}^{\prime} \rightarrow \mathrm{Na}^{\prime}$ migration but in a neighboring triple, exhibits only $E_{\text {mig }}=$ $0.5 \mathrm{eV}$. For long-range diffusion to the next triple higher energy barriers have to be overcome as shown in scenarios 3 and $4(\alpha$ : $E_{\text {mig }}>0.9 \mathrm{eV}, \beta: E_{\text {mig }}>0.8 \mathrm{eV}$ ). The structural changes from $\alpha$ - to $\beta-\mathrm{Na}_{4} \mathrm{P}_{2} \mathrm{~S}_{6}$ reduce the energy barriers for the scenarios by about $0.1 \mathrm{eV}$ but still differentiate between intra- and inter-triple migration. This said, the local method provides a different view than the BVEL calculations where the energy pathways almost align for intra- and inter-triple migration in the $\beta$ polymorph.

All NEB scenarios so far have in common that the pathway is through a tetrahedral interstitial that experiences electrostatic 

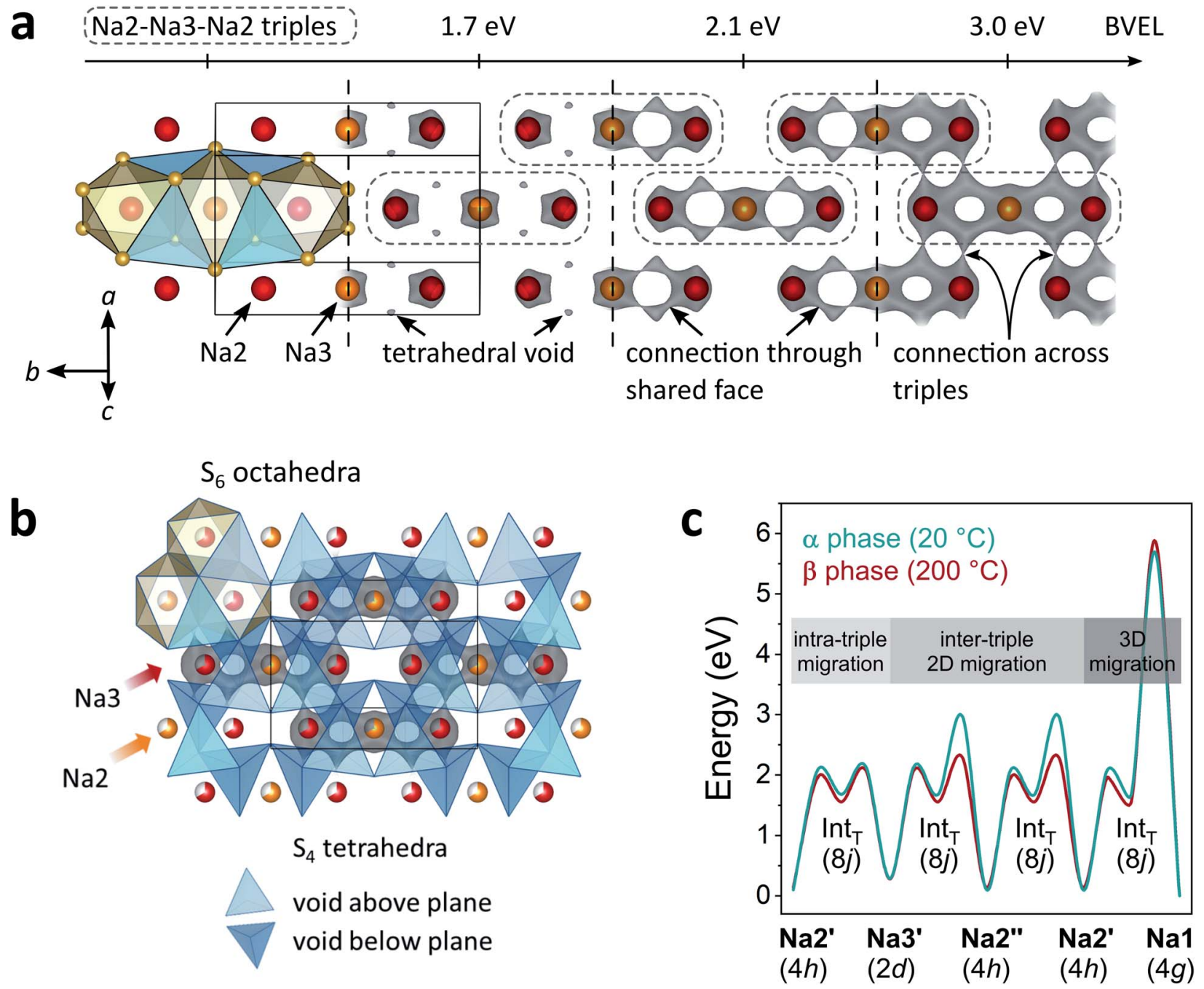

Fig. 5 (a) Evolution of bond valence energy landscapes in the (001/2) plane with increasing energy for the Na2-Na3-Na2 triple. (b) Overlay of BVEL and section of the crystal structure with tetrahedral interstitials (blue tetrahedra). (c) Energy diagram for intra-triple (') and inter-triple (") Na2 and $\mathrm{Na} 3$ migration and migration to a $\mathrm{Na} 1$ site illustrated for $\alpha$ - and $\beta-\mathrm{Na}_{4} \mathrm{P}_{2} \mathrm{~S}_{6}$ at $20{ }^{\circ} \mathrm{C}$ and $200{ }^{\circ} \mathrm{C}$, respectively.

repulsion from one (immobile) Na1 and one $\mathrm{Na} 2$ or $\mathrm{Na} 3$ ion that do not partake in the ion migration ( $c f$. Fig. 6). This is a rather unfavorable tetrahedral void, and hence unfavorable diffusion pathway. Recalculating the scenarios 2-4 with favorable tetrahedral voids having a free site next to the pathway results in a local energy minimum for the tetrahedral site (scenarios 5-7). The barriers for ion motion are reduced by about $1 / 2$ and can be expected to be even smaller in the real material because of the energy overestimation due to our DFT simplifications. The favorable scenarios 5-7 interconnect the entire $\mathrm{Na} 2 / \mathrm{Na} 3$ layer and enable long-range $\mathrm{Na}^{+}$migration in the $a b$ plane.

In the crystal structure exists only one tetrahedral site (Wyckoff position $8 j$ ). In $\alpha-\mathrm{Na}_{4} \mathrm{P}_{2} \mathrm{~S}_{6}$ this site is unfavorable due to the $\mathrm{Na}^{+}$ordering. However, in $\beta-\mathrm{Na}_{4} \mathrm{P}_{2} \mathrm{~S}_{6}$ the local environment changes, and under the condition that $\mathrm{Na} 2$ and $\mathrm{Na} 3$ are equally occupied as refined from the PXRD pattern, there are, in purely statistical terms, $44 \%$ unfavorable and $22 \%$ favorable tetrahedral voids (besides 33\% impossible voids with four or only one $\mathrm{Na}^{+}$, namely $\mathrm{Na} 1$, around). Every $\mathrm{Na} 2$ or Na3 site is surrounded by four of these tetrahedral voids (38\% probability that at least one of them is favorable), and the high number of five or six target sites can be reached from a Na2 or Na3 position, respectively ( $c f$. Fig. 5b). Thus, the probability for lowenergy ion migration pathways is high. In essence, the vacant sites are the key difference for the ionic conductivity in $\alpha$ - and $\beta$ $\mathrm{Na}_{4} \mathrm{P}_{2} \mathrm{~S}_{6}$.

Generally, vacancies are cumbersome to introduce by chemical substitutions to enhance the ionic conductivity. High amounts of sodium vacancies in thiophosphates are to our knowledge only known for $\mathrm{Na}_{11} \mathrm{Sn}_{2} \mathrm{PS}_{12}$, where they lead to superionic conductivity, ${ }^{24}$ but they have not been observed in more highly condensed thiophosphates yet.

Electrochemical impedance spectroscopy. After revealing the structural differences in $\mathrm{Na}_{4} \mathrm{P}_{2} \mathrm{~S}_{6}$ prepared via different synthetic routes, the ionic conductivity was tested with impedance spectroscopy on cold pressed pellets. The measurements were performed on solid-state synthesized powder (batches ss1 and ss2) resembling the $\alpha$ phase at room temperature, on 

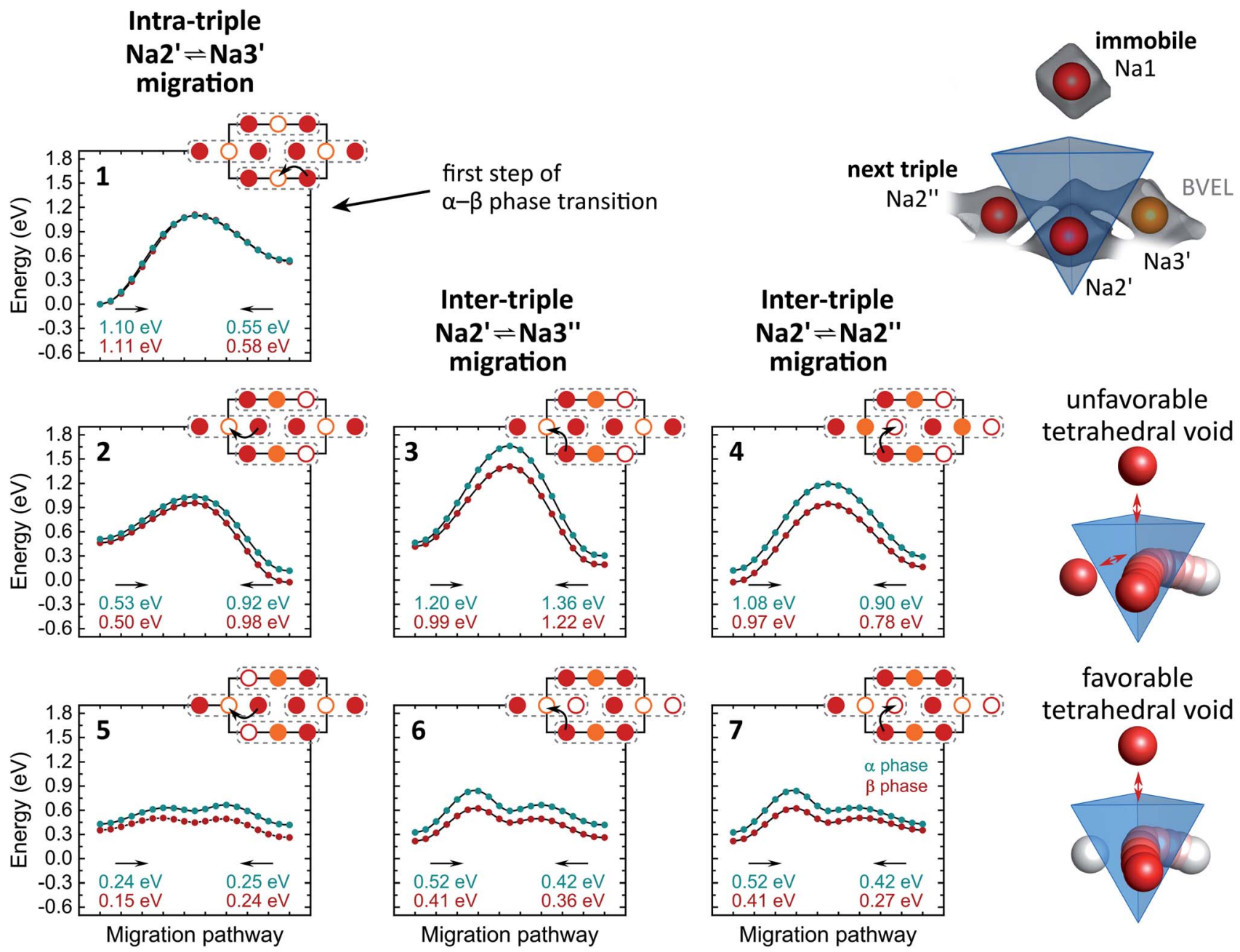

Fig. 6 Energy curves for $\mathrm{Na}^{+}$migration of scenarios 1-7 from NEB calculations. Corresponding migration energies are displayed under each curve. The $\mathrm{Na}^{+}$pathways in the Na2/Na3 layer are sketched with Na2 in red, Na3 in orange and the triples indicated with dashed grey lines. Un-/ occupied positions are displayed with empty/filled circles. Unfavorable and favorable tetrahedral voids are illustrated on the right side. The arrangement of tetrahedral voids within the unit cell can be found in Fig. 5b.

precipitated material ( $\mathrm{p} 1$ and $\mathrm{p} 2$ ) with a more $\beta$-like structure and inter- and intralayer disorder, and on annealed powder (a1) characterized by an intermediate structure with significant impurities as discussed above.

First, we present results on the Arrhenius behaviour of all samples well below the phase transition temperature $\left(\leq 100{ }^{\circ} \mathrm{C}\right)$. Representative complex impedance spectra in the Nyquistrepresentation are shown in Fig. 7a for all three $\mathrm{Na}_{4} \mathrm{P}_{2} \mathrm{~S}_{6}$ types. Please refer to the ESI $\dagger$ for a more detailed discussion of the impedance spectra interpretation and fitting. All spectra recorded at room temperature consist of only one (depressed) semicircle with an associated (averaged) capacitance of $7 \times$ $10^{-11} \mathrm{~F} \mathrm{~cm}^{-2}$ and $8 \times 10^{-11} \mathrm{~F} \mathrm{~cm}^{-2}$ for ss1 and ss2, $1 \times 10^{-10} \mathrm{~F}$ $\mathrm{cm}^{-2}$ and $4 \times 10^{-11} \mathrm{~F} \mathrm{~cm}^{-2}$ for $\mathrm{p} 1$ and $\mathrm{p} 2$, and $6 \times 10^{-11} \mathrm{~F} \mathrm{~cm}^{-2}$ for a1. A capacitance on the order of $10 \mathrm{pF}$ is usually expected for bulk processes, whereas a capacitance of $\mathrm{nF}$ is commonly attributed to grain boundaries. ${ }^{32,33}$ We checked all spectra for a possible second (grain boundary) semicircle that could overlap with the first high frequency arc by adding an additional $(R)$
(CPE) circuit in series. The resulting fits were unsatisfactory, both visually and as seen from calculated errors of the individual circuit units. Therefore, we conclude that only one process at ambient temperature, based on the associated capacitances presumably a bulk process, is observable for this material, similar to the findings of Krauskopf et al. for $\mathrm{Na}_{3} \mathrm{PS}_{4}{ }^{11}$

The room temperature ionic conductivity for solid-state $\mathrm{Na}_{4} \mathrm{P}_{2} \mathrm{~S}_{6}$ is about $7 \times 10^{-7} \mathrm{~S} \mathrm{~cm}^{-1}$, whereas the precipitated material has a higher mean conductivity of $2 \times 10^{-6} \mathrm{~S} \mathrm{~cm}^{-1}$. The difference may be directly attributed to the different polymorphs of $\mathrm{Na}_{4} \mathrm{P}_{2} \mathrm{~S}_{6}$ as we expect a higher conductivity for the $\beta$ like phase with $\mathrm{Na}^{+}$and vacancy disorder as well as structural defects. Considering the batch-to-batch variations, a smaller spread in conductivities is observed for the solid-state than for the precipitated material. This speaks for a more homogeneous solid-state product, in line with the high crystallinity of the $\alpha$ polymorph. For precipitated $\mathrm{Na}_{4} \mathrm{P}_{2} \mathrm{~S}_{6}$ the greater spread in conductivities is rationalized with the different sample histories due to slow or fast precipitation, re-crystallization, and 

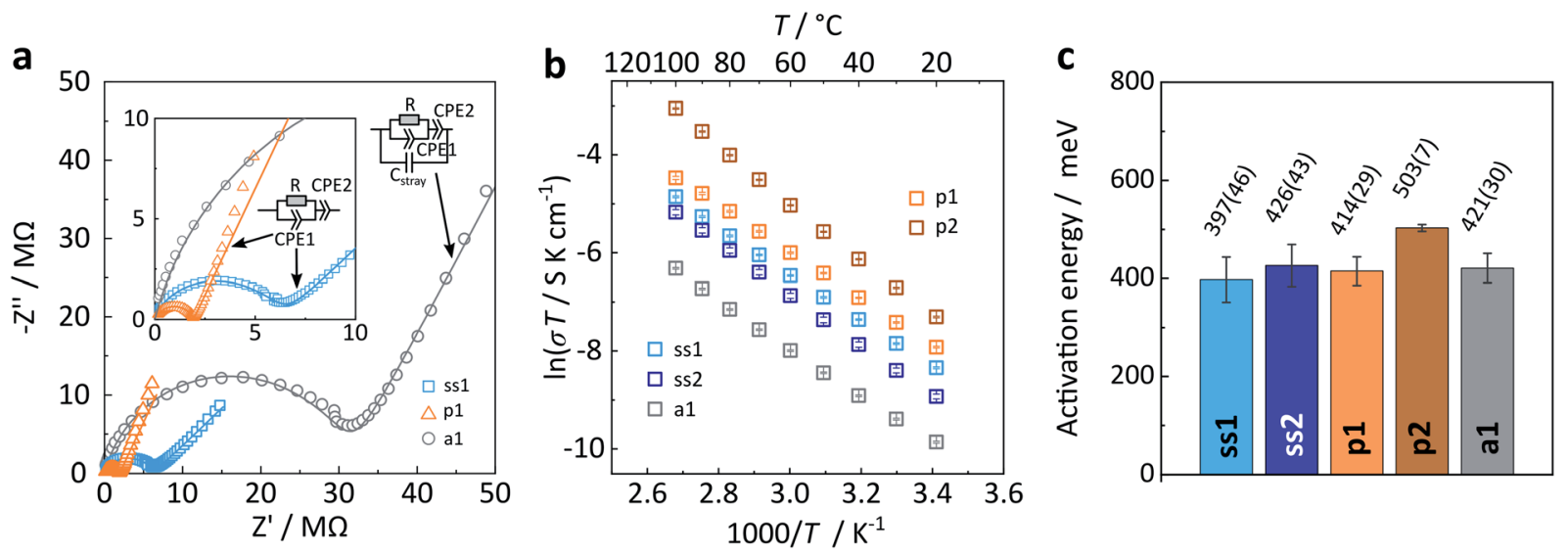

Fig. 7 (a) Exemplary Nyquist plots of solid-state $\alpha$, precipitated $\beta$-like, and annealed $\mathrm{Na}_{4} \mathrm{P}_{2} \mathrm{~S}_{6}$ measured at $20{ }^{\circ} \mathrm{C}$. (b) Arrhenius plots and (c) corresponding activation energies (averages of three different pellets, error bars indicated). ss1, ss2 - solid-state; p1, p2 - precipitated; a1 annealed batches.

dehydration, and also the varying amount of disorder in the material. With this in mind, we trace back the difference to the reported bulk conductivity for precipitated $\mathrm{Na}_{4} \mathrm{P}_{2} \mathrm{~S}_{6}\left(\sigma_{\text {bulk }}=3.4\right.$ $\left.\times 10^{-6} \mathrm{~S} \mathrm{~cm}^{-1}\right)^{29}$ to the higher dehydration temperature, namely $175{ }^{\circ} \mathrm{C}$ instead of $100{ }^{\circ} \mathrm{C}$ in this study. $\operatorname{Hood}^{29}$ found that at a dehydration temperature of $175^{\circ} \mathrm{C}$ the ionic conductivity was highest, whereas at $100{ }^{\circ} \mathrm{C} \mathrm{Na}_{4} \mathrm{P}_{2} \mathrm{~S}_{6}$ has a conductivity of around $5 \times 10^{-7} \mathrm{~S} \mathrm{~cm}^{-1}$. Annealed $\mathrm{Na}_{4} \mathrm{P}_{2} \mathrm{~S}_{6}$ has a room temperature ionic conductivity of $2.3 \times 10^{-7} \mathrm{~S} \mathrm{~cm}^{-1}$, which is considerably lower than for both solid-state and precipitated $\mathrm{Na}_{4} \mathrm{P}_{2} \mathrm{~S}_{6}$. We attribute this decrease to the variety of low $\mathrm{Na}^{+}$conducting thio-, thio/oxo- and oxo-phosphate impurities in this sample.

Next, activation energies of solid-state, precipitated, and annealed $\mathrm{Na}_{4} \mathrm{P}_{2} \mathrm{~S}_{6}$ were deduced from individual Arrhenius plots $\ln (\sigma T)$ as a function of inverse temperature (Fig. $7 \mathrm{~b}$ and $\mathrm{c}$ ). They are on the order of $0.40 \mathrm{eV}$ to $0.50 \mathrm{eV}$, with on average higher barriers for precipitated $\mathrm{Na}_{4} \mathrm{P}_{2} \mathrm{~S}_{6}$ compared to the solidstate material. The activation energy remains the same when annealing the precipitated p1 $\mathrm{Na}_{4} \mathrm{P}_{2} \mathrm{~S}_{6}$ sample. Based on our theoretical considerations and calculations we expect a lower activation energy for the $\beta$ polymorph. However, we observe that $\alpha$ and $\beta$-like $\mathrm{Na}_{4} \mathrm{P}_{2} \mathrm{~S}_{6}$ have a comparable mean activation energy. Real structure effects (and side phases), especially present in the precipitated sample, could be accountable for this unexpected result.

As reported before, first principles investigation of the electrochemical properties of $\alpha-\mathrm{Na}_{4} \mathrm{P}_{2} \mathrm{~S}_{6}$ performed by Rush et al. and $\mathrm{Li}$ et al. yielded an activation energy of $E_{\mathrm{A}} \approx 0.4 \mathrm{eV}$ (ref. 27 and 34 ) and $0.34 \mathrm{eV},{ }^{28}$ respectively. MD simulations suggest an activation energy of $0.41 \mathrm{eV}$ along with an experimentally confirmed activation energy of $0.39 \mathrm{eV} \cdot{ }^{28}$ All activation energies published so far are in good agreement with the values presented in this study. Although this level of agreement is encouraging and reinforces the notion that $\mathrm{Na}_{4} \mathrm{P}_{2} \mathrm{~S}_{6}$ has an activation energy of around $0.4 \mathrm{eV}$, one should be careful in comparing ionic conductivities and activation barriers reported by different groups, as reinforced by a recent benchmarking study. ${ }^{35}$ Not only sample history and preparation can have an impact on measured ionic conductivity, but also factors such as applied pressure and sample-electrode contacts. The study of Ohno et $a .^{35}$ found that the spread of reported activation values can be as big as $0.13 \mathrm{eV}$, depending on the setup and cell preparation used for measuring impedance on a one-batchmaterial distributed within different research groups.

Finally, the electronic conductivity of $\alpha$ (ss2) and $\beta$-like (p1) $\mathrm{Na}_{4} \mathrm{P}_{2} \mathrm{~S}_{6}$ was deduced from DC galvanostatic polarization measurements, establishing the material as a nearly pure sodium ion conductor with an electronic conductivity on the order of $\mathrm{nS} \mathrm{cm}^{-1}$ ( $c f$. ESI $\dagger$ ). This is at least two orders of magnitude lower than the ionic conductivity, hence the transference number for sodium ions is calculated to be $\geq 0.99$.

Overall, the measured transport data are in line with the other structure sensitive methods and confirm substantial differences between the $\mathrm{Na}_{4} \mathrm{P}_{2} \mathrm{~S}_{6}$ samples due to changes at the structural level, induced by different sample histories.

\section{Conclusion}

The development of all-solid-state sodium-ion batteries for scalable energy storage solutions requires fast sodium conducting solid electrolytes. Abundant resources and a cheap and green synthesis are seen as highly beneficial for large-scale application. Here, we have prepared $\mathrm{Na}_{4} \mathrm{P}_{2} \mathrm{~S}_{6}$ following two different routes, a solid-state and a precipitation method, and traced the resulting differences back to the following changes at the structural level.

First, a $\mathrm{Na}^{+}$and vacancy disorder-driven first order phase transition ( $\alpha$ to $\beta$ ) is observed for the solid-state synthesized material at temperatures around $160{ }^{\circ} \mathrm{C}$, which is associated with a symmetry change of the anion and changes in the population of the sodium sublattice. Second, the $\beta$-like polymorph is stabilized already at room temperature for precipitated $\mathrm{Na}_{4} \mathrm{P}_{2} \mathrm{~S}_{6}$, presumably through the assistance of inter- and intralayer defects.

Electrochemical impedance measurements and theoretical calculations reveal that the sodium-ion conduction is 
substantially affected by these structural differences. The key findings are as follows: using bond-valence calculations, lowenergy unoccupied sodium positions in both $\alpha$ - and $\beta-\mathrm{Na}_{4} \mathrm{P}_{2} \mathrm{~S}_{6}$ and possible short- and long-range $2 \mathrm{D} \mathrm{Na}^{+}$migration pathways especially in the $\beta$ polymorph were identified. Since the BVEL method does not capture local environments such as $\mathrm{Na}^{+}$ vacancies which are present in high amounts in $\mathrm{Na}_{4} \mathrm{P}_{2} \mathrm{~S}_{6}, \mathrm{NEB}$ calculations were used as a more local approach to demonstrate that the $\mathrm{Na}^{+}$disorder leads to many possible migration paths with a wide spread of $E_{\text {mig. }}$. Additional disorder, e.g. stacking faults, residual crystal water, or thiophosphate disorder in precipitated $\mathrm{Na}_{4} \mathrm{P}_{2} \mathrm{~S}_{6}$, even multiplies these possibilities. Finally, the ion transport for both polymorphs with different types of disorder were studied by impedance spectroscopy. The measurements suggest that the $\mathrm{Na}^{+}$conductivity in the precipitated sample is slightly higher than that of the solid-state sample $\left(2 \times 10^{-6} \mathrm{~S} \mathrm{~cm}^{-1}\right.$ vs. $7 \times 10^{-7} \mathrm{~S} \mathrm{~cm}^{-1}$ with $E_{\mathrm{A}} \approx$ $0.4 \mathrm{eV}$ for both materials at room temperature), which is consistent with the stabilization of the more conductive $\beta$ phase at room temperature in the precipitated sample.

In summary, the results point out that synthetic and postsynthetic treatment of solid electrolytes can substantially impact a material's properties. In fact, differences in sample preparation cannot only change the speciation and, hence, product outcome, but also change more subtle structural properties such as phase formation and stability range. Without critical investigation, important changes such as phase transitions with small structural changes and low heat tinting can be easily overlooked. The findings thus point to a rich and potentially unexplored phase space in thiophosphate solid electrolytes, and at the same time motivate a somewhat underappreciated approach for the design of improved solid electrolytes: phase formation through synthetic control.

\section{Conflicts of interest}

There are no conflicts to declare.

\section{Acknowledgements}

The authors acknowledge financial support by the Max Planck Society, the German Federal Ministry of Research and Education (BMBF), project 03XP0177B (FestBatt), the Center for Nanoscience (CeNS) and the Deutsche Forschungsgemeinschaft via the Cluster of Excellence e-conversion (EXC2089). We thank W. Hölle for single crystal measurements, the Computer Service group at MPI-FKF for providing computational facilities and N. M. Vargas-Barbosa for fruitful discussions. Open Access funding provided by the Max Planck Society.

\section{References}

1 Z. Zhang, Y. Shao, B. Lotsch, Y.-S. Hu, H. Li, J. Janek, L. F. Nazar, C.-W. Nan, J. Maier, M. Armand and L. Chen, Energy Environ. Sci., 2018, 11, 1945-1976.

2 T. Famprikis, P. Canepa, J. A. Dawson, M. S. Islam and C. Masquelier, Nat. Mater., 2019, 18, 1278-1291.
3 K. B. Hueso, M. Armand and T. Rojo, Energy Environ. Sci., 2013, 6, 734-749.

4 X. Lu, G. Xia, J. P. Lemmon and Z. Yang, J. Power Sources, 2010, 195, 2431-2442.

5 M. Guin and F. Tietz, J. Power Sources, 2015, 273, 1056-1064. 6 J. B. Goodenough, H. Y. P. Hong and J. A. Kafalas, Mater. Res. Bull., 1976, 11, 203-220.

7 T. J. Udovic, M. Matsuo, A. Unemoto, N. Verdal, V. Stavila, A. V. Skripov, J. J. Rush, H. Takamura and S.-i. Orimo, Chem. Commun., 2014, 50, 3750-3752.

8 L. Duchêne, R. S. Kühnel, D. Rentsch, A. Remhof, H. Hagemann and C. Battaglia, Chem. Commun., 2017, 53, 4195-4198.

9 A. Hayashi, K. Noi, A. Sakuda and M. Tatsumisago, Nat. Commun., 2012, 3, 856.

10 A. Hayashi, K. Noi, N. Tanibata, M. Nagao and M. Tatsumisago, J. Power Sources, 2014, 258, 420-423.

11 T. Krauskopf, S. P. Culver and W. G. Zeier, Inorg. Chem., 2018, 57, 4739-4744.

12 M. Jansen and U. Henseler, J. Solid State Chem., 1992, 99, 110-119.

13 T. Famprikis, J. A. Dawson, F. Fauth, O. Clemens, E. Suard, B. Fleutot, M. Courty, J.-N. Chotard, M. S. Islam and C. Masquelier, ACS Mater. Lett., 2019, 1, 641-646.

14 L. Zhang, D. Zhang, K. Yang, X. Yan, L. Wang, J. Mi, B. Xu and Y. Li, Adv. Sci., 2016, 3, 1600089.

15 S.-H. Bo, Y. Wang and G. Ceder, J. Mater. Chem. A, 2016, 4, 9044-9053.

16 T. Krauskopf, C. Pompe, M. A. Kraft and W. G. Zeier, Chem. Mater., 2017, 29, 8859-8869.

17 I.-H. Chu, C. S. Kompella, H. Nguyen, Z. Zhu, S. Hy, Z. Deng, Y. S. Meng and S. P. Ong, Sci. Rep., 2016, 6, 33733.

18 N. J. J. de Klerk and M. Wagemaker, Chem. Mater., 2016, 28, 3122-3130.

19 A. Hayashi, N. Masuzawa, S. Yubuchi, F. Tsuji, C. Hotehama, A. Sakuda and M. Tatsumisago, Nat. Commun., 2019, 10, 5266.

20 T. Fuchs, S. P. Culver, P. Till and W. G. Zeier, ACS Energy Lett., 2020, 5, 146-151.

21 A. Kuhn, R. Eger, J. Nuss and B. V. Lotsch, Z. Anorg. Allg. Chem., 2014, 640, 689-692.

22 C. Fritsch, A.-L. Hansen, S. Indris, M. Knapp and H. Ehrenberg, Dalton Trans., 2020, 49, 1668-1673.

23 Z. Zhang, E. Ramos, F. Lalère, A. Assoud, K. Kaup, P. Hartman and L. F. Nazar, Energy Environ. Sci., 2018, 11, 87-93.

24 M. Duchardt, U. Ruschewitz, S. Adams, S. Dehnen and B. Roling, Angew. Chem., Int. Ed., 2018, 57, 1351-1355.

25 T. Fincher, G. LeBret and D. A. Cleary, J. Solid State Chem., 1998, 141, 274-281.

26 S. Neuberger, S. P. Culver, H. Eckert, W. G. Zeier and J. Schmedt auf der Günne, Dalton Trans., 2018, 47, 1169111695.

27 L. E. Rush and N. A. W. Holzwarth, Solid State Ionics, 2016, 286, 45-50.

28 Y. Li, Z. D. Hood and N. A. W. Holzwarth, Phys. Rev. Mater., 2020, 4, 045406. 
29 Z. D. Hood, Lithium and sodium solid electrolytes for nextgeneration batteries: Bridging mechanistic understanding and their performance, $\mathrm{PhD}$ thesis, Georgia Institute of Technology, 2018.

30 S. Kmiec, A. Joyce and S. W. Martin, J. Non-Cryst. Solids, 2018, 498, 177-189.

31 R. Roy, D. K. Agrawal and H. A. McKinstry, Annu. Rev. Mater. Sci., 1989, 19, 59-81.
32 A. Kuhn, O. Gerbig, C. Zhu, F. Falkenberg, J. Maier and B. V. Lotsch, Phys. Chem. Chem. Phys., 2014, 16, 1466914674.

33 J. Fleig and J. Maier, J. Am. Ceram. Soc., 1999, 82, 3485-3493.

34 L. E. Rush Jr, First-principles investigation of electronic properties in sodium-ion electrolytes for solid-state battery materials electrolytes for solid-state battery materials, MSc thesis, Wake Forest University, 2017.

35 S. Ohno, et al., ACS Energy Lett., 2020, 5, 910-915. 